\title{
Lusioersily
}

\section{Tsunami threat in the Indian Ocean from a future megathrust earthquake west of Sumatra}

McCloskey, J., Antonioli, A., Piatanesi, A., Sieh, K., Steacy, S., Nalbant, S., Cocco, M., Giunchi, C., Huang, J., \& Dunlop, P. (2008). Tsunami threat in the Indian Ocean from a future megathrust earthquake west of Sumatra. Earth and Planetary Science Letters, 265(1-2), 61-81.

Link to publication record in Ulster University Research Portal

Published in:

Earth and Planetary Science Letters

Publication Status:

Published (in print/issue): 01/01/2008

\section{Document Version}

Publisher's PDF, also known as Version of record

\section{General rights}

Copyright for the publications made accessible via Ulster University's Research Portal is retained by the author(s) and / or other copyright owners and it is a condition of accessing these publications that users recognise and abide by the legal requirements associated with these rights.

\section{Take down policy}

The Research Portal is Ulster University's institutional repository that provides access to Ulster's research outputs. Every effort has been made to ensure that content in the Research Portal does not infringe any person's rights, or applicable UK laws. If you discover content in the Research Portal that you believe breaches copyright or violates any law, please contact pure-support@ulster.ac.uk. 


\title{
Tsunami threat in the Indian Ocean from a future megathrust earthquake west of Sumatra
}

\author{
John McCloskey ${ }^{\mathrm{a}, *}$, Andrea Antonioli $^{\mathrm{a}}$, Alessio Piatanesi ${ }^{\mathrm{b}}$, Kerry Sieh ${ }^{\mathrm{c}}$, Sandy Steacy ${ }^{\mathrm{a}}$, \\ Suleyman Nalbant ${ }^{\mathrm{a}}$, Massimo Cocco ${ }^{\mathrm{b}}$, Carlo Giunchi ${ }^{\mathrm{b}}$, JianDong Huang ${ }^{\mathrm{a}}$, Paul Dunlop ${ }^{\mathrm{a}}$ \\ ${ }^{a}$ Geophysics Research Group, School of Environmental Sciences, University of Ulster, Coleraine, BT52 1SA, Northern Ireland \\ ${ }^{\mathrm{b}}$ Seismology and Tectonophysics Department, Istituto Nazionale di Geofisica e Vulcanologia, Via di Vigna Murata 605, 00143-Rome, Italy \\ ${ }^{c}$ Tectonics Observatory, California Institute of Technology, Pasadena, United States
}

Received 2 July 2007; received in revised form 20 September 2007; accepted 20 September 2007

Available online 5 October 2007

Edited by: C.P. Jaupart

\begin{abstract}
Several independent indicators imply a high probability of a great $(M>8)$ earthquake rupture of the subduction megathrust under the Mentawai Islands of West Sumatra. The human consequences of such an event depend crucially on its tsunamigenic potential, which in turn depends on unpredictable details of slip distribution on the megathrust and how resulting seafloor movements and the propagating tsunami waves interact with bathymetry. Here we address the forward problem by modelling about 1000 possible complex earthquake ruptures and calculating the seafloor displacements and tsunami wave height distributions that would result from the most likely 100 or so, as judged by reference to paleogeodetic data. Additionally we carry out a systematic study of the importance of the location of maximum slip with respect to the morphology of the fore-arc complex. Our results indicate a generally smaller regional tsunami hazard than was realised in Aceh during the December 2004 event, though more than $20 \%$ of simulations result in tsunami wave heights of more than $5 \mathrm{~m}$ for the southern Sumatran cities of Padang and Bengkulu. The extreme events in these simulations produce results which are consistent with recent deterministic studies. The study confirms the sensitivity of predicted wave heights to the distribution of slip even for events with similar moment and reproduces Plafker's rule of thumb. Additionally we show that the maximum wave height observed at a single location scales with the magnitude though data for all magnitudes exhibit extreme variability. Finally, we show that for any coastal location in the near field of the earthquake, despite the complexity of the earthquake rupture simulations and the large range of magnitudes modelled, the timing of inundation is constant to first order and the maximum height of the modelled waves is directly proportional to the vertical coseismic displacement experienced at that point. These results may assist in developing tsunami preparedness strategies around the Indian Ocean and in particular along the coasts of western Sumatra.
\end{abstract}

(C) 2007 Elsevier B.V. All rights reserved.

Keywords: tsunami; Sumatra; megathrust; earthquake; hazard

* Corresponding author.

E-mail address: j.mccloskey@ulster.ac.uk (J. McCloskey).

\section{Introduction}

The great magnitude 9.2 Sumatra-Andaman earthquake of 26 December 2004 resulted from up to $20 \mathrm{~m}$ of slip on the Sunda megathrust which, in turn, produced 
vertical seafloor displacements approaching $5 \mathrm{~m}$ in the deep water above the Sunda trench southwest of the Nicobar Islands and off-shore Aceh (Vigny et al., 2005; Subarya et al., 2006; Piatanesi and Lorito, 2007; Chlieh et al., 2007). These vertical movements created a large tsunami that propagated throughout the Indian Ocean, killing more than 250,000 people. On March 282005 the megathrust ruptured again in the magnitude 8.7 Simeulue-Nias earthquake. In this case, while locally the slip on the megathrust was as high as $12 \mathrm{~m}$ (Briggs et al., 2006) the resulting tsunami waves nowhere exceeded $4 \mathrm{~m}$ (Geist et al., 2005) and the smaller death toll was largely due to strong ground shaking. The contrast was only partly due to the smaller energy release of the second earthquake. The greatest slip in December 2004 produced large vertical seafloor displacements under deep water, resulting in a tsunami with high potential energy and, according to Green's law (Leblond and Mysak, 1978), large wave amplification toward the coast. By contrast, the maximum slip in the March 2005 event produced seafloor movements in relatively shallow water, thus resulting in a tsunami with smaller potential energy and lower wave amplification. Finally, the tsunami waves in December reached highdensity centres of population through deep water. Much of the coast of Aceh experienced destructive waves, some as high as $30 \mathrm{~m}$, which killed more than one hundred thousand people (http://www.tsunami.civil. tohoku.ac.jp/sumatra2004/report.html, 2004). It is clear that the contrasting tsunamis produced by these earthquakes was the result of complex interactions between their moment release, distributions of slip and the local and regional bathymetry.

The Simeulue-Nias earthquake nucleated in an area whose stress had been increased by the SumatraAndaman earthquake (McCloskey et al., 2005). Followup studies (Nalbant et al., 2005; Pollitz et al., 2006) show that it has additionally perturbed the surrounding stress field and has, in particular, brought the megathrust under the Batu and Mentawai Islands closer to failure. Recent aseismic slip (Hsu et al., 2006; Chlieh et al., 2007) has further increased the stress (Fig. 1). Paleogeodetic studies show that the megathrust under the Batu Islands is slipping at about the rate of plate convergence (Natawidjaja et al., 2004) while under Siberut Island it has been locked since the great 1797 earthquake and has recovered nearly all the strain released then (Natawidjaja et al., 2006). Here the megathrust is clearly well advanced in its seismic cycle and may be ripe for interaction stress triggering. South of Siberut, the subduction zone has not failed since 1833, which implies the potential for about $8 \mathrm{~m}$ of slip extending more than $600 \mathrm{~km}$ south-eastward from about $0.5^{\circ} \mathrm{S}$. The exact location of the southeastern end of the 1833 rupture is unknown, but it may be north of Enganno Island (Fig. 1), which lies in a region of high megathrust seismicity (Newcomb and McCann, 1987). The seismic potential of the megathrust between Enganno and the Sunda Strait is unknown.

The tsunamigenic potential of future ruptures beneath the Mentawai Islands would not only depend on the extent of rupture propagation and resultant magnitude; it would be largely determined by unpredictable details of the slip distribution, and how this slip interacts with the local and regional bathymetry. The outcome of these complex interactions would, of course, be far from academic. Cities on the west coast of Sumatra, notably Padang and Bengkulu, lie on low coastal plains and would appear to be particularly vulnerable to tsunamis generated by Mentawai segment earthquakes (Fig. 1). It is certain that historical earthquakes have produced damaging tsunamis in western Sumatra although, as in the case of the 2004 and 2005 earthquakes, it would appear that scalar measures of earthquake potency, such as seismic moment, are poor predictors of their tsunamigenic potential. Thus the $1907 M=7.6$ Simeulue earthquake appears to have produced a greater tsunami than either the 1861 (M8.3$8.5)$ or the $2005(M=8.7)$ earthquakes that occurred in the same area with likely similar source ruptures (Newcomb and McCann, 1987). A recent work (Borrero et al., 2006) has attempted to assess the tsunami threat to the main cities of western Sumatra from a Mentawai Islands earthquake. They used deterministic scenarios employing uniform slip on the fault plane to simulate tsunamis which would result from a series of six possible events: models of the 1797 and 1833 earthquakes and four simulations of larger events whose ruptures extended for $750 \mathrm{~m}$. This study is an important and urgent attempt to advise preparedness strategies for Sumatra but we note that these scenarios, and, for example their choice of uniform slip distributions implicitly under-state the complexity of the problem, thereby oversimplifying the potential hazard assessment. Here we take a different and complimentary approach by acknowledging the fundamental uncertainties associated with the processes of earthquake rupture and tsunamigenesis and explore a much wider range of possible scenarios all of which incorporate a realistic degree of heterogeneity. We employ well-constrained numerical simulations of megathrust rupture to calculate the seafloor displacements that would result from suites of complex, scale invariant rupture geometries. These displacements are used as initial conditions for numerical simulations of tsunami wave generation and propagation, in an attempt to estimate the energies of tsunamis around 


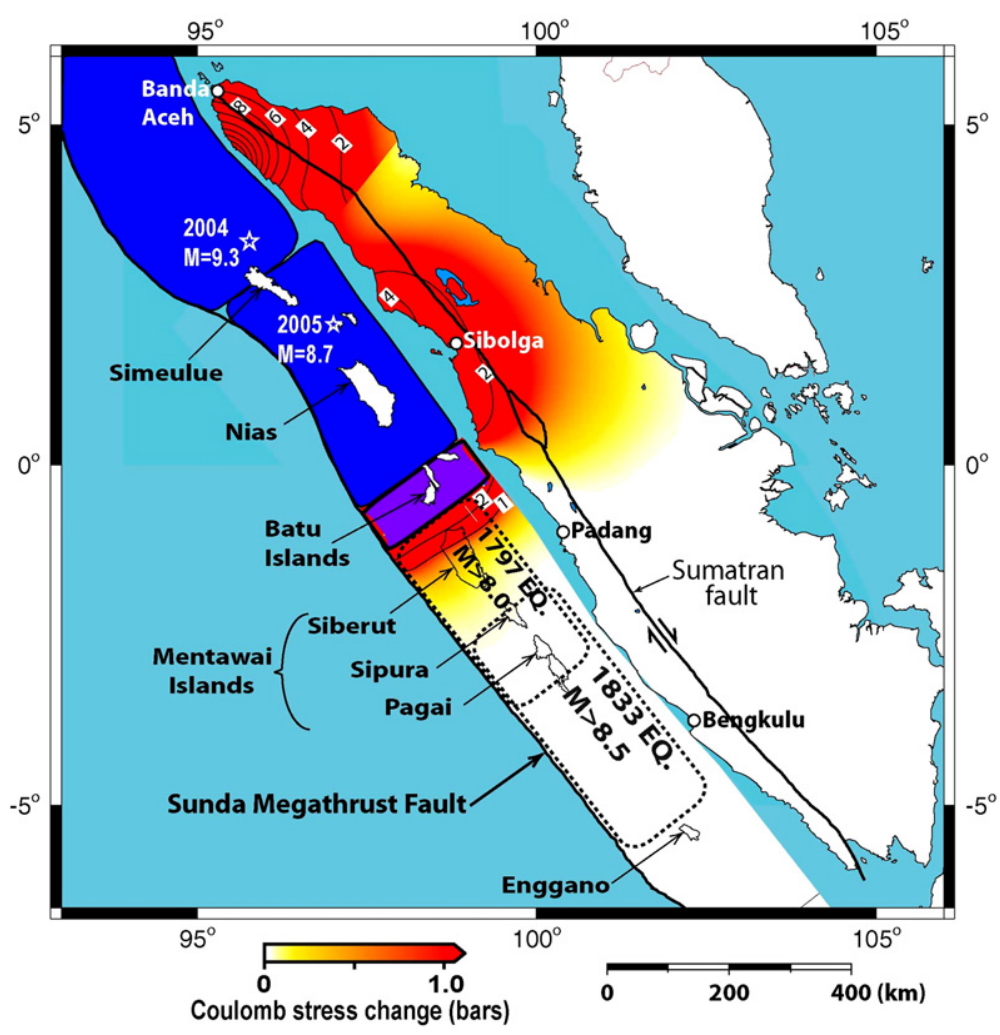

Fig. 1. Historical earthquakes and current interaction stresses on the Sunda megathrust. Solid lines indicate the traces of important faults. Dotted lines indicate outlines of main historical earthquake ruptures as estimated by paleogeodetic studies. Stars indicate epicentres and dark blue areas indicate extent of recent great earthquake ruptures. Current interaction stresses, shown in the yellow-red colour scale have been calculated for this study and include coseismic stress and both the effect of after-slip on the Simeulue-Nias source region and aseismic slip under the Batu islands. Colours indicate the stress, calculated at a depth of $10 \mathrm{~km}$, resolved onto the appropriate mechanism (right-lateral strike slip for on-land Sumatra and thrust for the subduction zone). (For interpretation of the references to colour in this figure legend, the reader is referred to the web version of this article.)

the entire Indian Ocean that would result from a range of plausible Mentawai segment earthquakes. We concentrate in particular on the distribution of wave heights that might be experienced in western Sumatra.

\section{Simulations}

\subsection{Fault segment selection}

In attempting to forecast future potential tsunamigenic earthquakes the seismogenic fault segments must first be defined. Here we consider both stress interactions with recent earthquakes including postseismic slip and slip due to weak plate coupling as well as the paleoseismology and geodesy of the region to advise this definition. Interaction stress with recent megathrust earthquakes as well as with aseismic slip up-dip from the main asperities that ruptured in the 2005 earthquake and beneath the Batu Islands now exceeds 3 bars south of the Batu Islands and total almost 1 bar under Siberut Island (Fig. 1); an order of magnitude greater than the stress that is believed to have triggered the 2005 event. Interaction stresses with the recent events continue to grow in response to viscoelastic relaxation of the lower crust (Nalbant et al., 2005; Pollitz et al., 2006). Paleogeodetic evidence shows that the megathrust beneath Siberut has been locked firmly since 1797 (Natawidjaja et al., 2006) and is thus well advanced in its seismic cycle (Borrero et al., 2006) and is therefore a plausible candidate for triggered failure. Accordingly, in this study, we assume that the next great Mentawai Islands earthquake will nucleate somewhere in this area of positive interaction and all scenario earthquakes in this study include rupture of the segment under Siberut, though its main conclusions are robust to nucleation in other places.

Where will this rupture stop? Fault segmentation and the existence and longevity of barriers to rupture 
propagation that define the termination of earthquakes, are the subject of much debate and research. The remarkable coincidence of the rupture areas of the 1861 and 2005 earthquakes provides persuasive evidence both for the existence and for the persistence of a barrier to the north under Simeulue Island and to the south under the Batu Islands. In both cases the barrier is likely caused by changes in the constitutive properties of the fault due to the subduction of regions of high relief on the oceanic plate (e.g. Kopp et al., 2006) though the effect on pore-fluid pressure of subduction thick sediment piles has also been suggested as an explanation of segmentation (Prawirodirdjo et al., 1997). Additionally, paleogeodetic evidence from coral studies shows unambiguously that the megathrust under the Batu Islands has been slipping aseismically at about the rate of plate convergence for more than 50 years (Natawidjaja et al., 2006). The stress deficit resulting from this slip, whatever its cause probably defined the southern termination of the 2005 earthquake and would probably terminate the northward propagation of any rupture nucleating under Siberut. Consequently, all scenario earthquakes have northern terminations here.

The likely location of the southern rupture termination is more problematic. The 1797 earthquake ruptured the megathrust for over $300 \mathrm{~km}$ southward from the Batu Islands to south Pagai Island. The 1833 event, on the other hand, ruptured from Enganno Island in the south to Sipura Island overlapping with the earlier event by about $100 \mathrm{~km}$ (Fig. 1). Thus the barrier that controlled the southward termination of the 1797 event failed to stop the northward propagation of the next earthquake that occurred only 36 years later. These observations underscore the great difficulty in the deterministic prediction of the extent of an earthquake even given the detailed historical and geodetic information that is available for the megathrust under the Mentawai Islands. The complex interplay between stress, strength and slip history, including the poorly understood effects of dynamic rupture stresses and aseismic processes, all contribute to this difficulty (see for example Steacy and McCloskey, 1999). Here we make the following assumptions: a) the southern termination of the 1797 event and both the northern and southern terminations of the 1833 event were caused by barriers to rupture propagation; b) while any future Mentawai Islands earthquake may rupture any of these barriers, its southern extent will likely be defined by one of them; c) earthquake rupture will not propagate beyond the Sunda Straight. On this basis we define four rupture lengths as follows. 1) Rupture of the 200-km long patch of the megathrust, from the Batu Islands to the north of Sipura that failed in 1797 but not in 1833. 2) A repeat of the 1797 earthquake rupture, between the Batu and south of the Pagai Islands with a total length of about $330 \mathrm{~km}$. 3) Rupture of the $630-\mathrm{km}$ long patch that includes the 1797 and 1833 ruptures and extends south to Enganno Island. 4) A worst case 800-km long rupture scenario extending from beneath Siberut Island through the poorly understood Enganno region to the Sunda Straight. We argue that, while other rupture scenarios are certainly possible, maybe even probable, these scenario segments are likely to cover a sufficient range of earthquakes so that we might explore the full range of possible tsunami threats to the Sumatran coast.

\subsection{Slip distributions}

It has become increasingly clear (Geist, 2002; Geist et al., 2005) that the distribution of slip on the fault has a first order effect on the tsunamis that result from any earthquake on it. The use of smooth slip models, while producing forecasts that are more easily assimilated into preparedness schemes, fundamentally understates the inherent complexity and unpredictability of the process of seismogenesis and therefore oversimplifies the assessment of tsunami risk. Here, we ensure that a wide variety of slip distributions, with slip concentrated at different parts of the megathrust, are examined for each scenario fault segment. Earthquake slip has been observed to have a heterogeneous (fractal) spatial distribution and we use fractal distributions of slip for all scenarios, though this choice does not strongly affect the main results. The choice of a fractal distribution does, however, impose, via its autocorrelation function, a statistical control on postseismic strain. Our choice of a fractal dimension of 2.1, is consistent with observation (Mai and Beroza, 2002) and constrains the average gradient of slip on the megathrust to be on the order of $10^{-4}$. Thus slip of $10 \mathrm{~m}$ at any location on the fault should not, in general, drop to zero in less than about $100 \mathrm{~km}$ in any direction on the fault plane. In consequence, almost all of our models, whose maximum slips are generally $>10 \mathrm{~m}$, involve rupture of the entire down-dip width (about $180 \mathrm{~km}$ ) of the megathrust for at least some of the length of the rupture. While ruptures are permitted to propagate upward to the seafloor we impose a constraint on the gradient of slip at the along-strike rupture terminations which refuses simulations with high slip there. In only a few of the shorter ruptures where maximum slip is located at either up-dip near the trench or down-dip near the brittleductile transition is the rupture confined in down-dip extent. We note that this is not a strong condition and is 
consistent with the great majority of inversions for fault slip. We also note that inversions that are based on geodetic measurements, such as recent inversions for slip on the 2005 earthquake have produced slip inversions that are also spatially confined in down-dip extent (Banerjee et al., 2007). We argue that our simulations are not inconsistent with these inversions once the limitations of spatial coverage and of resolution are considered. The slip distributions here, while maintaining finite levels for most of the fault segments under consideration, fall asymptotically to zero far from the regions of high slip (see slip distributions in Figs. 3 and 4). Finally, none of the main conclusions presented here is significantly altered by allowing some anomalous events with limited extension of down-dip width.

The slip is integrated over the entire rupture to yield the event moment and we use the observed weak correlations between both maximum slip and moment with fault rupture length (Henry and Das, 2001) to place upper bounds on slip and energy release for any given structure and thereby to reject obviously unphysical simulations. The shorter ruptures produce model earthquakes with magnitudes between $8.1-8.3$ whereas the $840 \mathrm{~km}$ ruptures generate events of magnitude up to about 9.2. For each fault length, several hundred realisations of slip distribution are examined. In the first instance those events whose moment release exceeds the maximum for that fault length or that have features, such as patches of high slip intersecting one or more model boundary and that are therefore unlikely to be seen in reality, are discarded. The remaining models are assessed for conformity with expected concentrations of strain exposed by paleogeodetic studies. Seafloor displacements are finally calculated for the 100 or so modelled slip distributions that are judged, by this assessment, to represent the most likely future earthquakes. We chose about equal numbers for each fault length.

\subsection{Seafloor displacements}

Seafloor displacements resulting from any distribution of slip are calculated using a customised, 3D, heterogeneous, finite-element model. The numerical computations are performed with the commercial finiteelements (FE) software MARC (Msc software). The Sumatra region is discretized into 33820 8-node isoparametric brick elements. The computational domain extends away from the fault plane to avoid border effects and is characterized by a horizontally nonuniform resolution (coarser in the far field to optimize the CPU time). The spatial resolution of the elements on the fault plane is $30 \mathrm{~km}$ along strike and $25 \mathrm{~km}$ down-dip.
The Sunda trench in the area of interest is approximately linear, strikes at about $140^{\circ}$ and extends from the equator to about $6.5^{\circ} \mathrm{S}$. The plate interface dips at about $15^{\circ}$ resulting in a down-dip seismogenic width of about $180 \mathrm{~km}$. This fault plane geometry is used for all simulations. The fault plane discontinuity is defined by contact elements to prevent the copenetration of the surfaces. The slip is assured by gap elements connecting the node pairs. The heterogeneous slip values derived from the synthetic slip distributions are directly applied to the nodes belonging to the fault plane. Our predictions are validated with the results obtained with a full analytical model (using a boundary element program 3D-def coded by (Gomberg and Ellis, 1994): the displacement components predicted by our model without topography and lateral rheological variations satisfactorily reproduce the predictions of the flat laterally homogeneous model.

The finite-element numerical model allows a better approximation of the geometry and lateral variations of the lithosphere along the rheologically complex megathrust region of western Sumatra with respect to the usual assumptions of analytical models based on dislocations embedded in a homogeneous isotropic half-space. Together with the trench topography, our model includes elastic layering where the hanging wall block, continental and subducting oceanic lithosphere are characterized by different elastic properties. In our model, the bathymetry is derived from seismic reflection profiles (Kopp et al., 2001) and the stratified elastic medium extends down to $450 \mathrm{~km}$. We assign different elastic properties to the accretionary wedge, continental and subducting oceanic lithosphere (Turcotte and Schubert, 2002). Fig. 2 shows the differences between the fully heterogeneous model with topography and a simple flat stratified model for one of the slip distribution adopted in our simulations. The differences of up to $40 \mathrm{~cm}$ in the seabed vertical displacements lead to differences in the water height greatly amplified by the bathymetry and can lead to maximum tsunami wave differences of metres.

\subsection{Tsunami modelling}

High resolution of the bathymetric model, particularly near the coast, is crucial for robust estimation of tsunami wave heights in shallow water. While we employ the ETOPO2 data, with a resolution of 2 ", for the ocean wide simulations, we integrate four spatially referenced bathymetric and topographic data sets to model the bathymetry of the Sumatran coast. Specifically we: 1) digitise the largest-scale hydrographic 


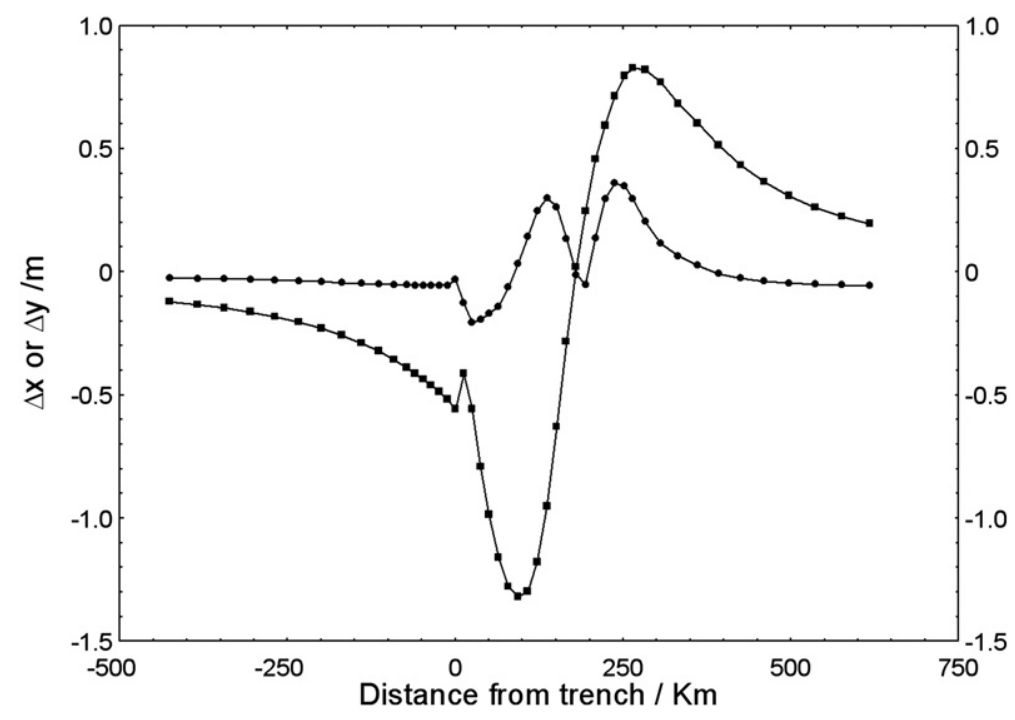

Fig. 2. Horizontal and vertical differences in the displacement between the fully $3 \mathrm{D}$ numerical model and a flat stratified analytical model. The profile is perpendicular to the trench line and close to the city of Padang. Distances are in $\mathrm{km}$ from the trench. Displacements are in metres.

charts for near-shore bathymetry; 2) emphasise the weighting of the shoreline in the interpolation by digitising orthorectified Landsat ETM + images (Tucker et al., 2004) with a spatial resolution of $30 \mathrm{~m}$; 3) stabilise the location of the shoreline during interpolation by integration of SRTM digital elevation data on Sumatra and the off-shore islands and 4) use ETOPO2 data in deep water seaward of the trench. These datasets are combined and interpolated onto a 0.5 " grid and 2 " for Western Sumatra and Amphi-Indian Ocean simulations respectively. We have checked the convergence of our computations with respect to the grid spacing. Considering as reference the results of a computation performed with 0.25 " of grid spacing, we found that we underestimate the wave heights along the coast of Sumatra by $2 \%$ and $20 \%$ when using 0.5 and 2 " of grid spacing respectively. We have therefore concluded, given the variability of the results below, that the 0.5 " grid spacing is a good compromise between accuracy of the results and computational efficiency.

Tsunamis propagate in the sea as gravity waves obeying classic laws of hydrodynamics. Since their wavelength is much larger than the sea depth, they behave as long waves propagating in shallow water. Here, we solve numerically the nonlinear shallow water equations using a finite difference scheme on a staggered grid; the scheme we employ is derived from the SWAN model of reference (Mader, 2004). The initial sea-surface elevation is assumed to be equal to the coseismic vertical displacement of the seafloor calculated above, and the initial velocity field is assumed to be zero everywhere
(Satake, 2002). We apply a pure reflection boundary condition along the true coastline at which the depth has everywhere been set to $10 \mathrm{~m}$ to avoid numerical instabilities. This boundary condition ensures that all the tsunami kinetic energy is converted into potential energy at the coast and thus, while we do not simulate the complex processes of inundation that are controlled by fine-scale details of the near-shore topography, our predicted coastal wave heights include both the effect of shoaling to $10 \mathrm{~m}$ depth and the interaction with the solid boundary. Simulated wave heights at the coast therefore represent a first order estimate of the smoothed local runup height. Near-field wave heights include the effect of static, vertical coseismic seafloor movements. Since earthquake rupture velocities are large with respect to tsunami phase speeds, we assume instantaneous rupture. This assumption becomes weaker for longer rupture lengths but sensitivity analyses indicate that the effect is on the order of $5 \%$ for the longest ruptures modelled in this study. The model returns the time varying values of water depth at each model node. For each simulation we record both the maximum wave height at every node ocean wide as well as synthetic mareograms for selected model tide gauges around the Indian Ocean and for a cluster of locations on western Sumatra and its off-shore islands.

\subsection{Dependence of wave height on details of slip distribution}

So that we might systematically investigate the dependence of predicted tsunami height on the slip 
distribution, and in particular on the location of the maximum slip, we carried out a set of 9 simulations in addition to the main model runs. From a $4096 \times 4096 \mathrm{~km}$ simulated slip distribution we chose an isolated patch of high slip. By moving a $630 \times 180 \mathrm{~km}$ window, representing the megathrust south of the Batu Islands around this high slip patch we constructed nine slip distributions with slip maxima occurring at systematically different locations with respect to the fore-arc morphology. We were particularly interested in the effect of the islands on the propagation of tsunamis and located the high slip region: 1) high on the megathrust thus generating large seafloor displacements in deep water to seaward of the fore-arc high, 2) at intermediate depth under the islands and deep on the fault near the brittleductile transition. These down-dip locations were then repeated along strike near Siberut, near the Pagai Islands and between South Pagai and Enganno Island (see Fig. 1).

The entire sequence of modelling for a $630 \mathrm{~km}$ $M=8.7$ earthquake is illustrated in Fig. 3 .

\section{Results}

This systematic study of tsunamis generated from large number of earthquakes simulated using complex slip distributions and sophisticated elastic displacement models to provide the boundary conditions for a tsunami model simulating wave propagation of a well-constrained bathymetric model offers an opportunity, not only to estimate the tsunami threat posed by the next great Mentawai earthquake but also to examine systematic relationships between the earthquake source and the predicted tsunami amplitudes. We will firstly look at the general relationships between tsunami amplitudes and the broad measures of earthquake energy before looking at the role of the off-shore islands and large-scale features of the bathymetry in controlling tsunami propagation. Sections 3.3 and 3.4 look in more detail at the predicted tsunami threats around the Indian Ocean and to western Sumatra respectively. Finally, we will demonstrate two strong relationships between tsunami travel times and amplitudes and the long-wavelength flexing of the crust in the near field of the earthquake.

\subsection{General relationships}

Fig. 4A shows the relationship between the global maximum tsunami wave heights and the maximum slip on the simulated earthquakes. This linear relationship has been observed in the field where it has been referred to as Plafker's rule (Okal and Synolakis, 2004). It is interesting to note that, for our simulations, the coseismic slip appears to provide a strong constraint on the wave height; only in a very small number of cases does the height of the highest wave exceed the maximum coseismic slip.

Of more interest in the present study is the relationship between earthquake energy and predicted wave heights at the centres of population, particularly in western Sumatra. Fig. 4B shows the scaling of maximum wave height observed at Padang with the magnitude of the earthquake. There is clearly well defined relationship though the scatter approaches a factor of ten for all earthquake magnitudes, a feature that is an intrinsic property of the physics of tsunamigenesis rather than of error in the measurement of maximum tsunami height or of magnitude; such real scatter is observed in many crustal processes (Scholz, 1990 and references therein). We note that similar results have been shown for a Monte Carlo simulation of local tsunami wave heights for Acapulco due to a megathrust earthquake on the interface between the North-American plate and subducting Cocos plate (Geist and Parsons, 2006).

\subsection{The role of islands and bathymetry}

A systematic examination of the relationship between slip distribution and the locations of the off-shore islands and the large-scale features of the bathymetry go some way in explaining large scatter of the data in Fig. 4. While the events in Fig. 5, for example, have approximately the same magnitude, the waves experienced at any place along the Sumatran coast have, in general, very different energies. Event A (Fig. 5A), whose maximum slip occurred to seaward of northern Siberut, resulted in moderate waves of up to $1.3 \mathrm{~m}$ at Padang whereas the waves resulting from event $\mathrm{B}$ (Fig. 5B) reach almost $8 \mathrm{~m}$. Clearly the location of the high slip region to seaward of a major fore-arc island ensured that Padang was greatly sheltered from the worst waves. The importance of the fore-arc islands is further demonstrated by the difference in energies experienced on the adjacent Sumatran coast resulting from events A and C (Fig. 5C). Whereas Siberut protects the coast near Padang, the smaller elevation of the forearc high between the Pagai Islands and Enganno ensures that Bengkulu experiences relatively greater tsunami heights from the rupture of an asperity with a similar relative position. It should be pointed out, however, that while the coast near Bengkulu appears to be as exposed as was, for example, the coast of western Aceh in 2004, even between Pagai and Enganno the fore-arc high rises 
almost to the sea surface and still offers a greater degree of protection than was afforded there. This means that only in extreme cases does Bengkulu experience tsunami heights of greater than $10 \mathrm{~m}$. The worst case scenarios for any coastal city results from a Mentawai event that breaches the Enganno Island barrier experiencing high slip under the fore-arc basin south of there. In this type of low-probability event, Bengkulu can experience waves of up to $15 \mathrm{~m}$. Waves predicted in this study never approach the $30 \mathrm{~m}$ maximum wave heights observed in 2004.

\subsection{Amphi-Indian Ocean results}

For every simulation we recorded the maximum wave height experienced at every model node as well as the tsunami time series for a set of indicative locations around the Indian Ocean. A set of observations from an energetic earthquake that illustrates the main conclusions is shown in Fig. 3D. A robust, and general, observation is that Indian Ocean coasts hit hard by the December 2004 tsunami will experience much smaller waves from future rupture of the Mentawai segment. Many areas badly affected in December 2004, most notably northern Aceh Province, Thailand and eastern India experience relatively small waves for all modelled Mentawai earthquakes. For sites on the western coast of the Indian Ocean, this is explained by the orientation of the Mentawai segment, which results in much of the tsunami energy being directed toward the southwest, into the Southern Ocean. All simulated tsunami waves propagating to the east and north are stopped by Sumatra and by its western islands. Some distant coasts, however, could expect to experience moderate wave

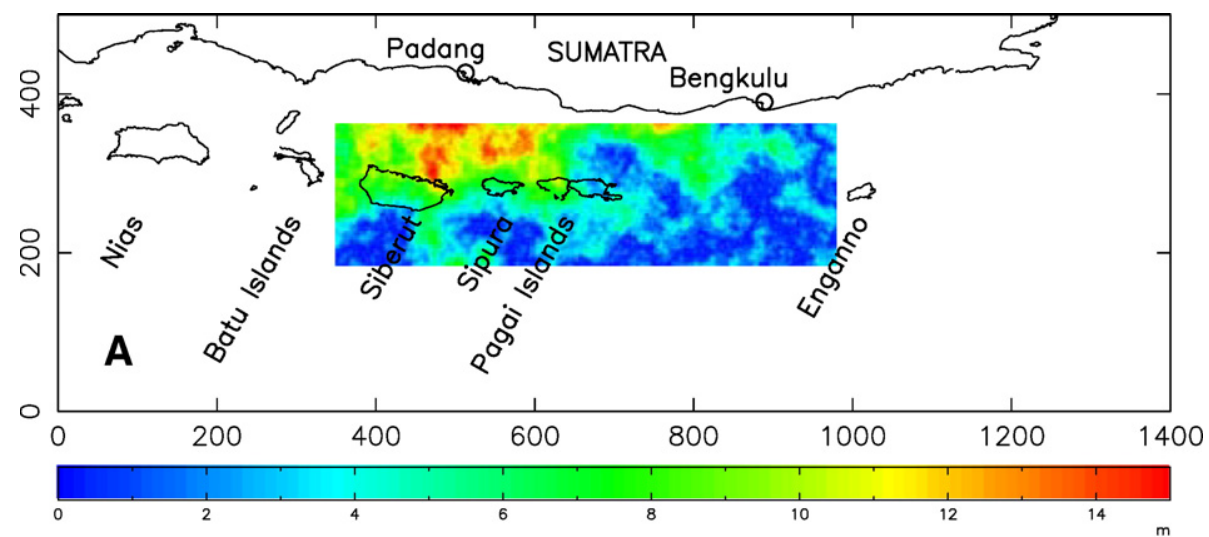

B

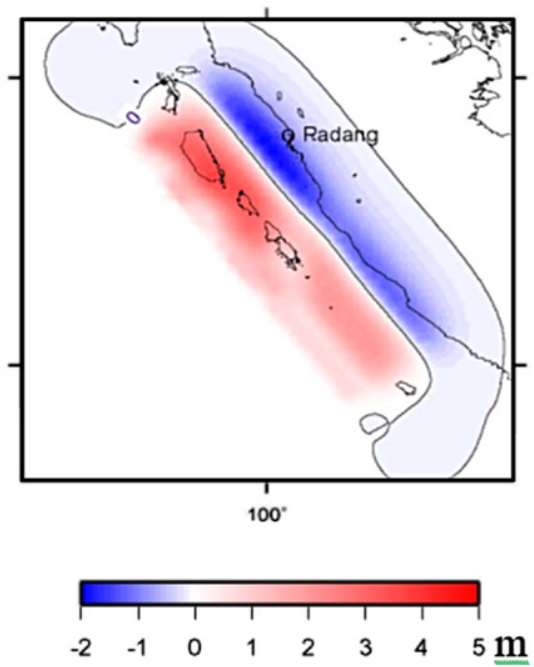

Fig. 3. The full modelling process for a $630 \mathrm{~km}$ earthquake rupture. Colour scales shown here are used throughout the rest of the paper. A. Slip distribution projected vertically upward from the inclined megathrust-plane to the surface. B Vertical coseismic seafloor displacements calculated for the event. C. Maximum waveheights predicted at $5 \mathrm{~km}$ intervals along the west coast of Sumatra. D. Maximum wave heights predicted for the Indian Ocean with synthetic mareograms predicted for some indicative coastal locations. The scales of all synthetic mareograms are identical. 


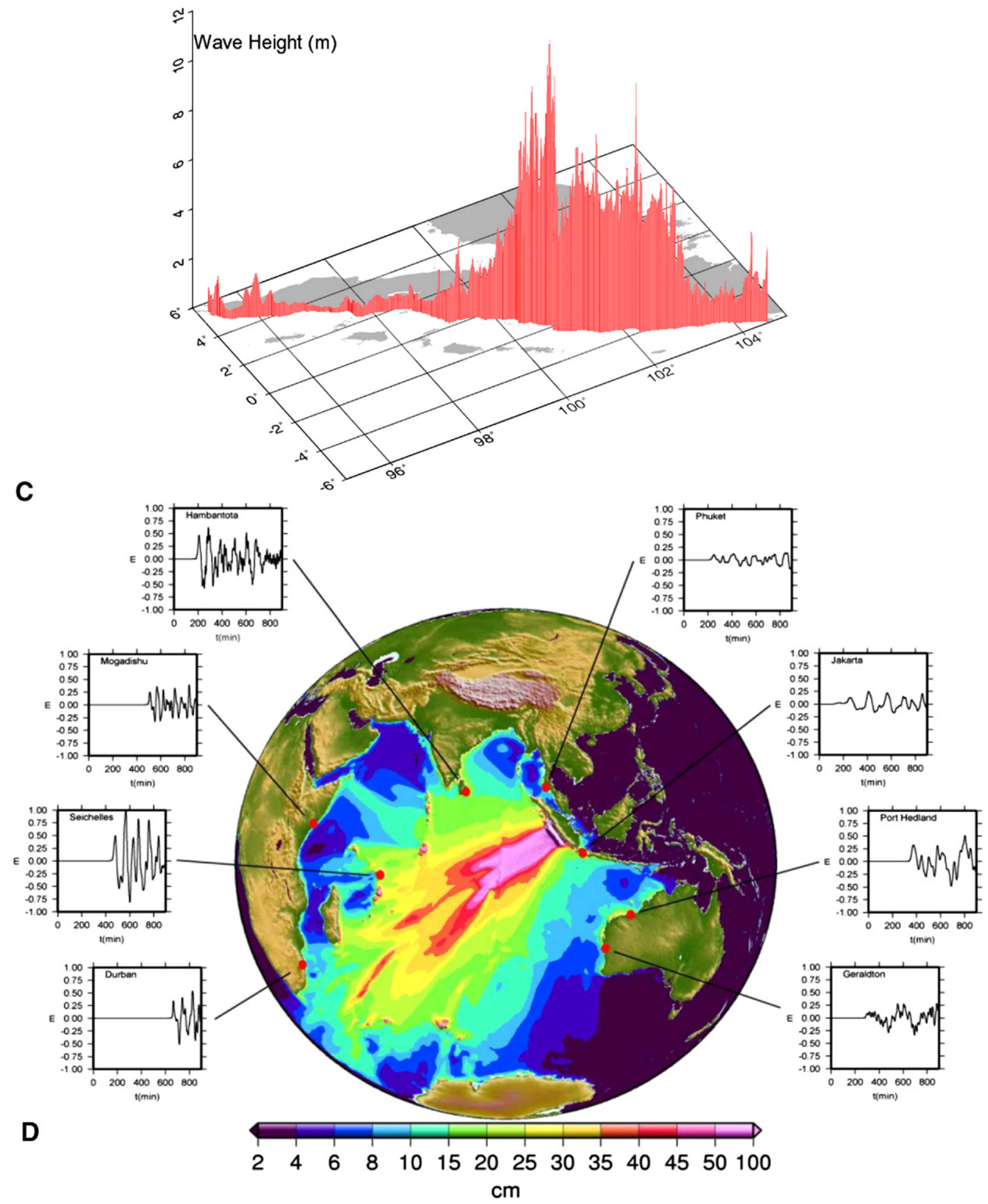

Fig. 3 (continued).

heights. Port Headland, NW Australia, Hambantota, Sri Lanka and the Seychelles all experience modelled waves with heights greater than $0.5 \mathrm{~m}$ for some of the more energetic simulations and these waves could be amplified by local bathymetric focusing to generate significant local hazards. 

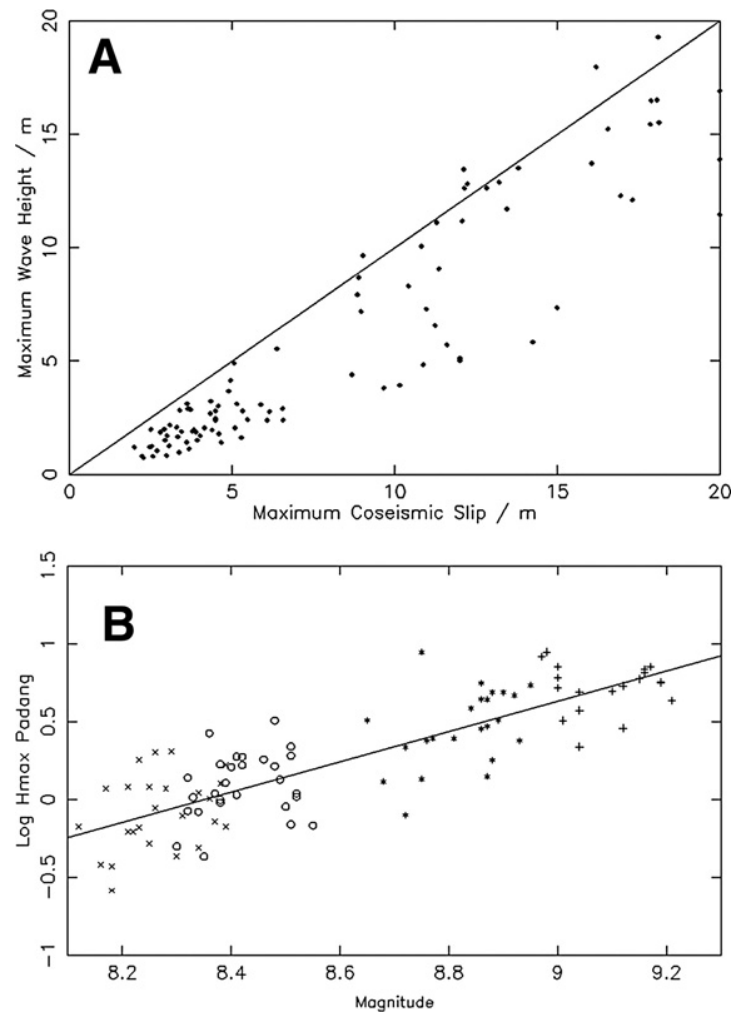

Fig. 4. General scaling relationships between measures of simulated earthquake energy and predicted wave height of the simulated tsunami waves. A) Maximum wave height as a function of maximum coseismic slip on the earthquake. Note this reproduction of Plafker's law relates maximum wave height observed anywhere with the maximum displacement anywhere on the fault. B) Log maximum wave height (Hmax in $\mathrm{m}$ ) observed here in Padang as a function of magnitude. The seismic moment is calculated from $M_{0}=\mu \sum_{A} \Delta \mathrm{u}$ where $\mu$ is the shear modulus (taken as $50 \mathrm{GPa}$ ), $\Delta \mathrm{u}$ is the slip on a cell of unit area and the summation is over all cells slipping in the event. The moment magnitude, $M_{\mathrm{w}}$, is then given by the usual moment-magnitude relation. Note the order of magnitude scatter in predicted wave height for a given magnitude.

\subsection{Western Sumatra}

The distribution of wave heights forecast for western Sumatra and its coastal cities in particular has been a central focus of this work. Modelled wave heights (Fig. 6A) here are generally smaller than those experienced in Aceh province in 2004 despite the proximity of the Sumatran coast to simulated centres of high slip and large seafloor displacements. Fig. 6A has several important features with respect to hazard on western Sumatra. Firstly and most notably is the extreme variability of the wave heights predicted for the scenarios modelled here. The maximum predicted waves for any location are often more than an order of magnitude greater than the minimum. Additionally, the lateral variation of the heights is also strong illustrating clearly the role of small scale changes in the local bathymetry. Note also the limited northern extent of high predicted waves. All the scenario earthquakes here have northern terminations under the Batu Islands. The proximity of the megathrust to the coast strongly reduces the effect of geometric spreading and limits the worst waves to coasts that are broadside-on to the rupture. Note, however, that there is a significant rise in the impact to the west of Aceh province that may be due either to local bathymetric amplification or the impact of reflected waves on a coast line that is entirely unprotected by off-shore islands or shallows. This again emphasises the importance of the fore-arc high in determining many aspects of tsunami hazard for western Sumatra. Despite the large energy release from all of our simulations and the proximity of the megathrust to the coast, only $3 \%$ of our simulations, for example, predict wave heights greater than $10 \mathrm{~m}$ for Bengkulu (Fig. 6B); no predicted waves for Padang exceed $10 \mathrm{~m}$. The worst cases simulated in this study are broadly consistent with the extreme scenarios modelled in other studies (e.g. Borrero et al., 2006) but reflect more strongly the uncertainty in the rupture process that can produce very different results even assuming the certainty of the occurrence of an earthquake with $M>8$.

We also note that the possibility of rupture propagation south of Enganno Island, which is a feature of all the extreme scenarios, is controversial. The seismicity between Enganno Island and the Sunda Strait is significantly different than that to the north and it has been argued that this segment may have a much lower seismic potential (Habermann et al., 1986; Newcomb and McCann, 1987); there are, for example, no historical records of great earthquakes here. Our results, therefore, indicate a very small probability for any city experiencing off-shore waves greater than $10 \mathrm{~m}$ when the frequency-size distributions in Fig. 4B are rescaled to reflect the undoubtedly smaller likelihood of the threatened earthquake breaking the Enganno Island barrier.

While waves greater than $10 \mathrm{~m}$ appear unlikely, many simulations do nonetheless indicate serious tsunami hazard. $10 \%$ of simulations for Padang, for example, produce maximum wave heights of more than $6.5 \mathrm{~m}$ while the worst $10 \%$ for Bengkulu have amplitudes greater than $8 \mathrm{~m}$. For both cities more than $40 \%$ of all simulations produce waves of greater than $2 \mathrm{~m}$ and more than $20 \%$ generate waves higher than $5 \mathrm{~m}$. 


\subsection{Near-field tsunamis}

The greatest threat posed by a potential Mentawai Islands earthquake is to the large populations living on coasts a small distance from the megathrust. It is at these near-field locations, including the cities of Padang and
Bengkulu, that the greatest loss of life is possible as a result both of strong ground shaking and from a tsunami. Due to the proximity of the seismogenic fault, it is here also that early warning is most difficult. Usage of the term 'near-field' varies between disciplines and to avoid confusion we here adopt the following formal
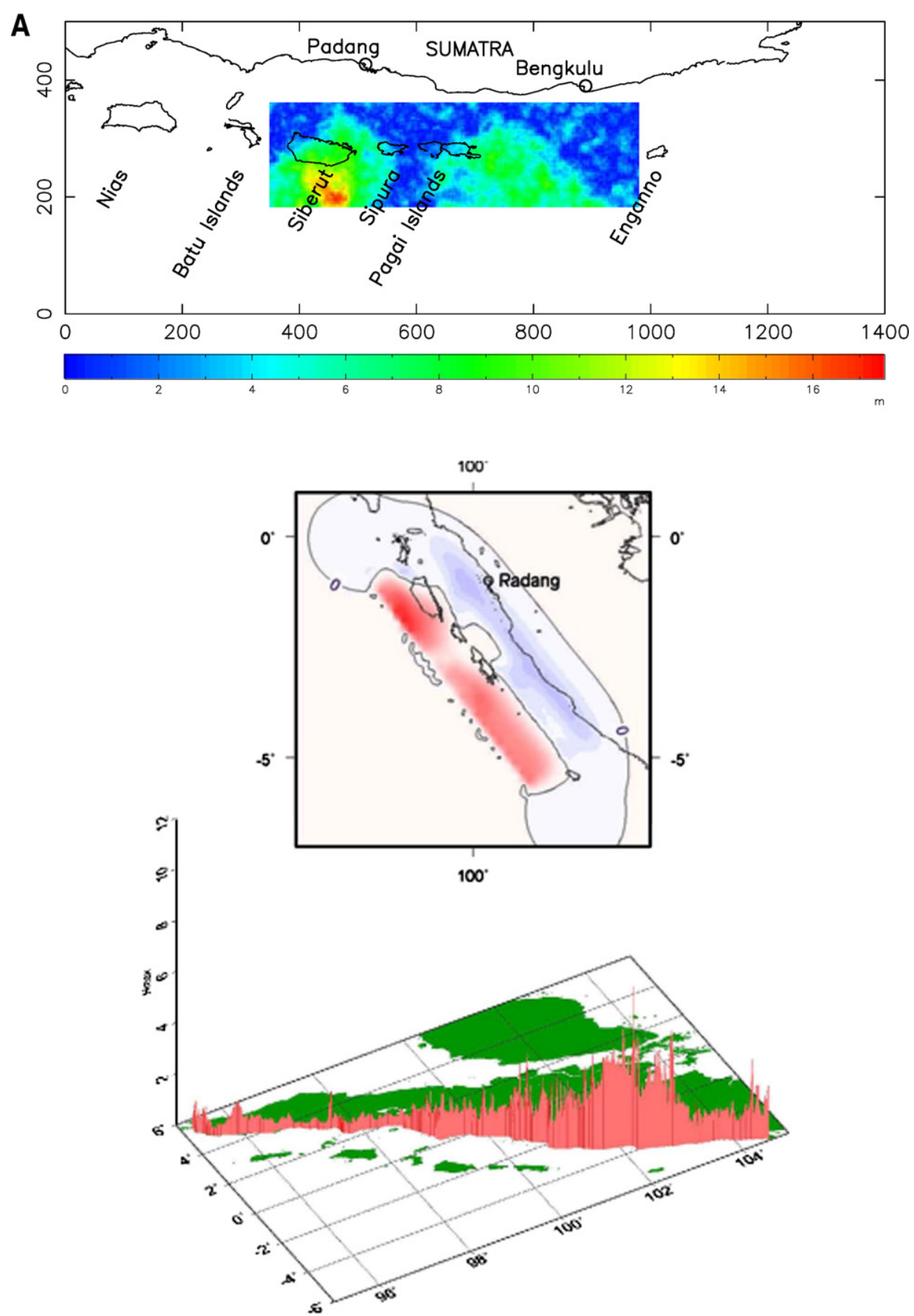

Fig. 5. Selected simulations from the asperity location study. Each panel shows the slip distribution, the seafloor displacement and the wave heights for western Sumatra for a single event. Magnitudes of simulated events are 8.91, 8.96 and 8.94 respectively. Colour scales given in Fig. 3. 

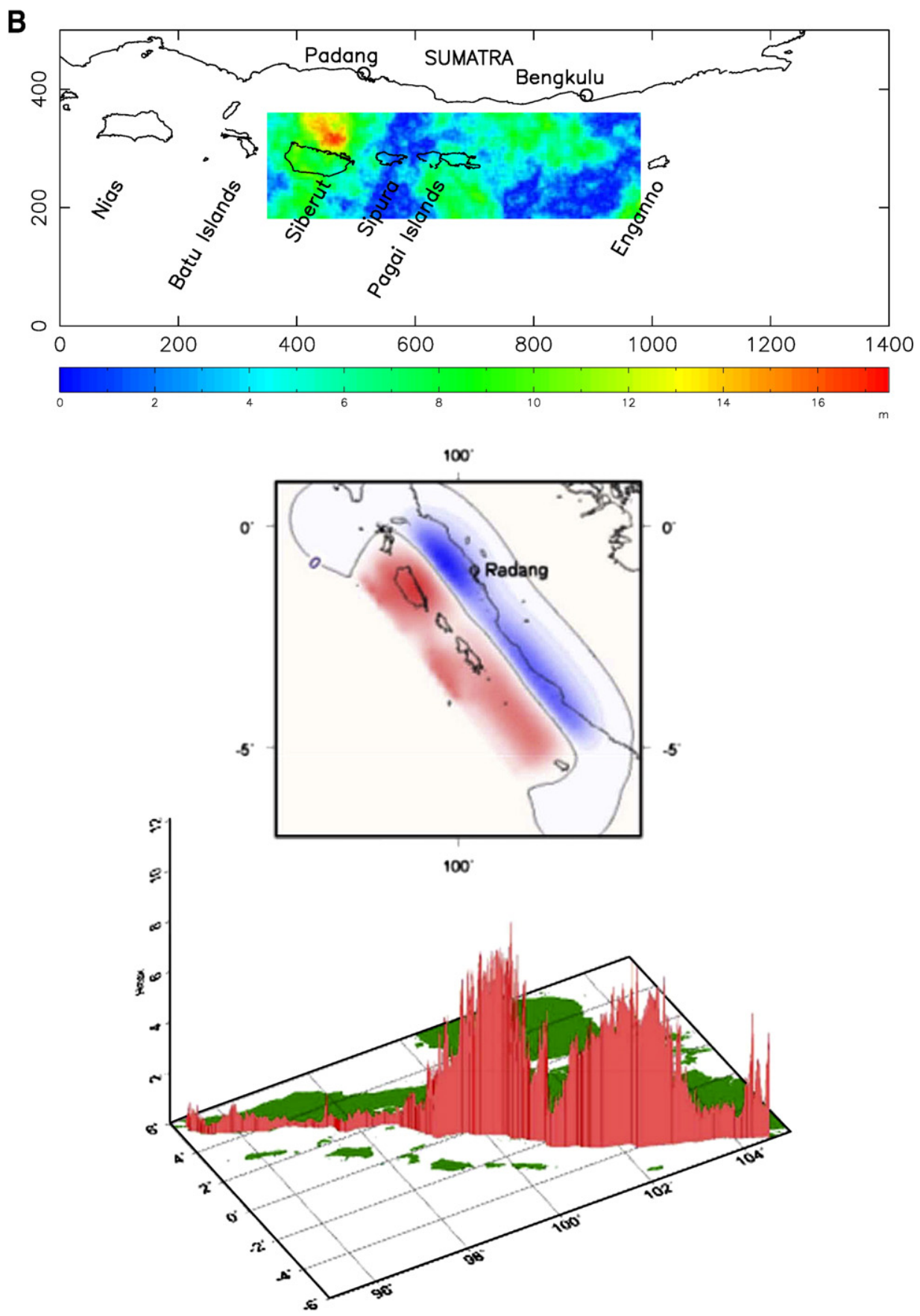

Fig. 5 (continued).

definition: The near field is the set of locations that experience a vertical coseismic displacement from the tsunamigenic earthquake that is measurable by current GPS technology, on the order of $1 \mathrm{~cm}$. This includes four model tide gauges, Padang, Siberut Bay, Siberimanua and Bulasat for all modelled earthquakes with the addition of Bengkulu for the $630 \mathrm{~km}$ and $840 \mathrm{~km}$ events that is not in the near field of shorter ruptures (Fig. 8A). Surprisingly, we find that, despite the dependence of tsunamigenesis on details of the slip complexity, both the timing of inundation and its maximum height in the near field are dominated by 

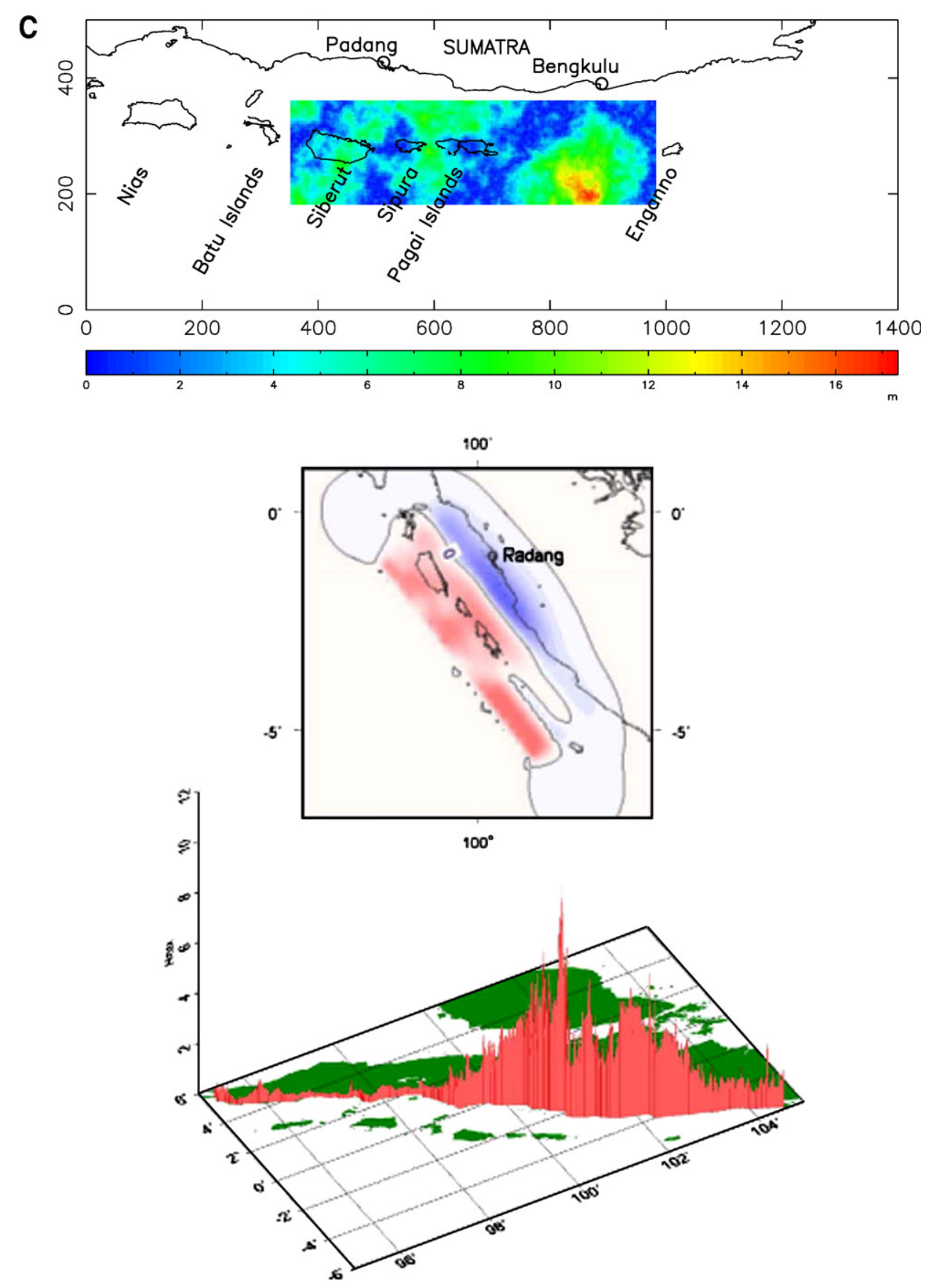

Fig. 5 (continued).

long-wavelength components of coseismic crustal flexure (McCloskey et al., 2007). We will illustrate these findings firstly with reference to synthetic mareograms produced by $330 \mathrm{~km}$ ruptures recorded at Padang before showing that they appear to be general for all near-field model tide gauges and for all events.
Fig. 7 shows the synthetic mareograms recorded at Padang from all the $330 \mathrm{~km}$ simulations. The most striking feature of these plots is their qualitative similarity; they all contain the same phases with essentially the same arrival times. While a detailed description of these phases is beyond the scope of this 

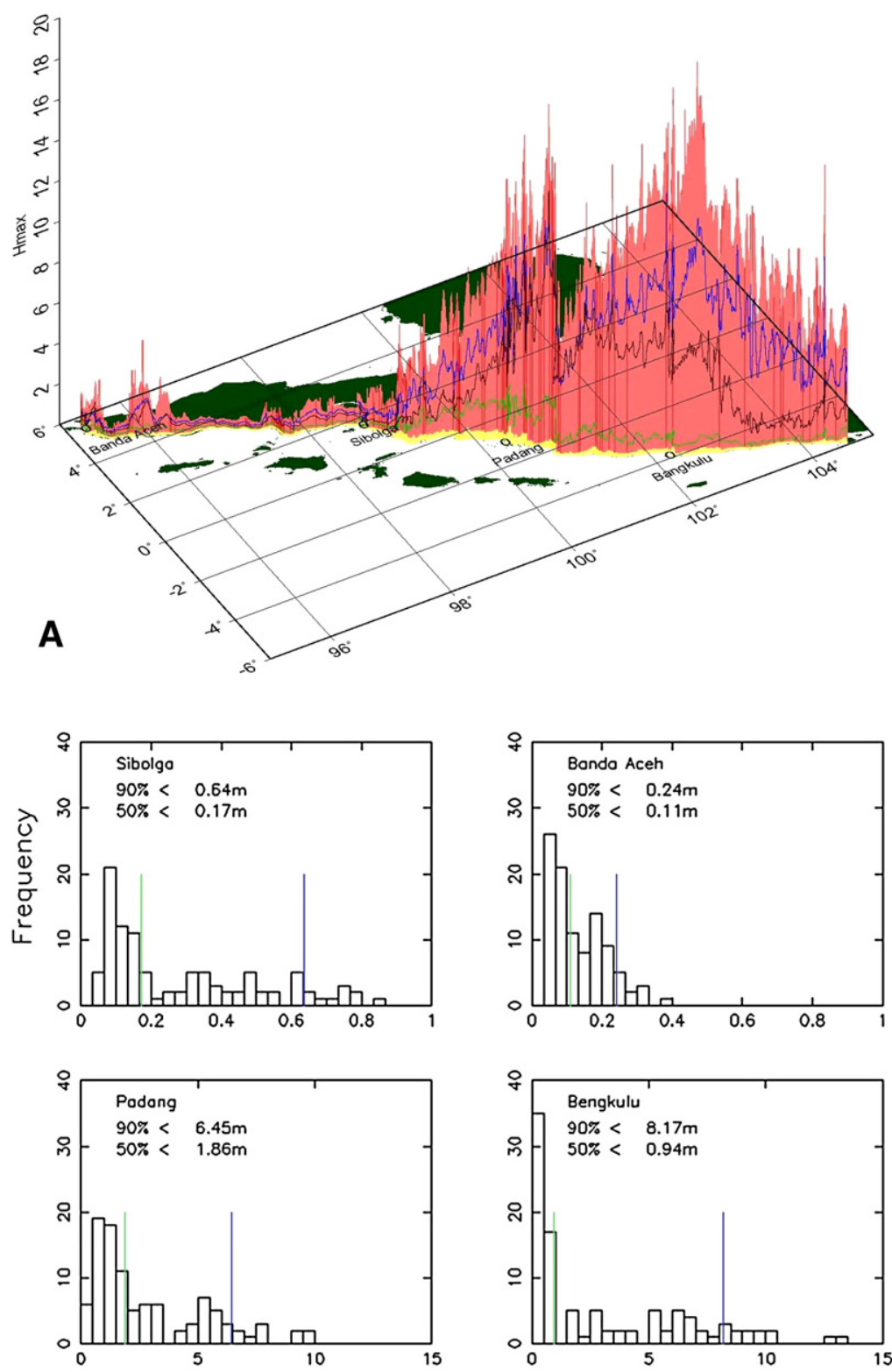

B

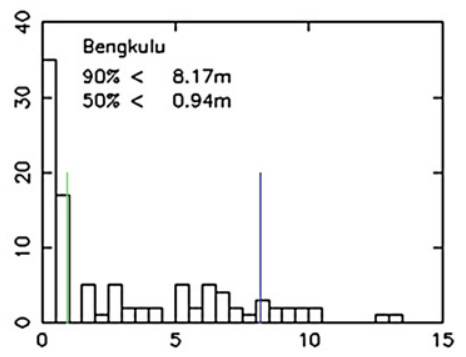

Max Wave Height / $\mathrm{m}$

Fig. 6. Distribution of maximum wave heights on Sumatran coast for all simulations. In both diagrams green and blue lines indicate median and $10 \%$ excedence values respectively; the black line in A indicates the $90 \%$ excedence height. All wave heights are reported at $10 \mathrm{~m}$ depth though at the true coast, see text for explanation. A) Wave heights along the Sumatran coast indicating locations of major coastal cities. Red bars and yellow bars indicate maximum and minimum wave heights respectively. B) Distributions of wave heights experienced at major cities. Median and $10 \%$ excedence values are noted in each panel. Notice the different wave height scales for northern cities.

paper, it is clear that their similarity implies that, despite the complexity of the slip distributions, the shape of the mareograms, but not their amplitude, is dominated by global features of the coseismic deformation coupled with the bathymetry. Thus, for example, the first downgoing phase that is always observed at Padang is caused by the downward motion of the seafloor under the deep water of the fore-arc basin relative to the shore there; this pattern is common to every earthquake simulated in this study observed from Padang. The other phases are similarly controlled by the interaction of the large-scale features of the deformation and the 


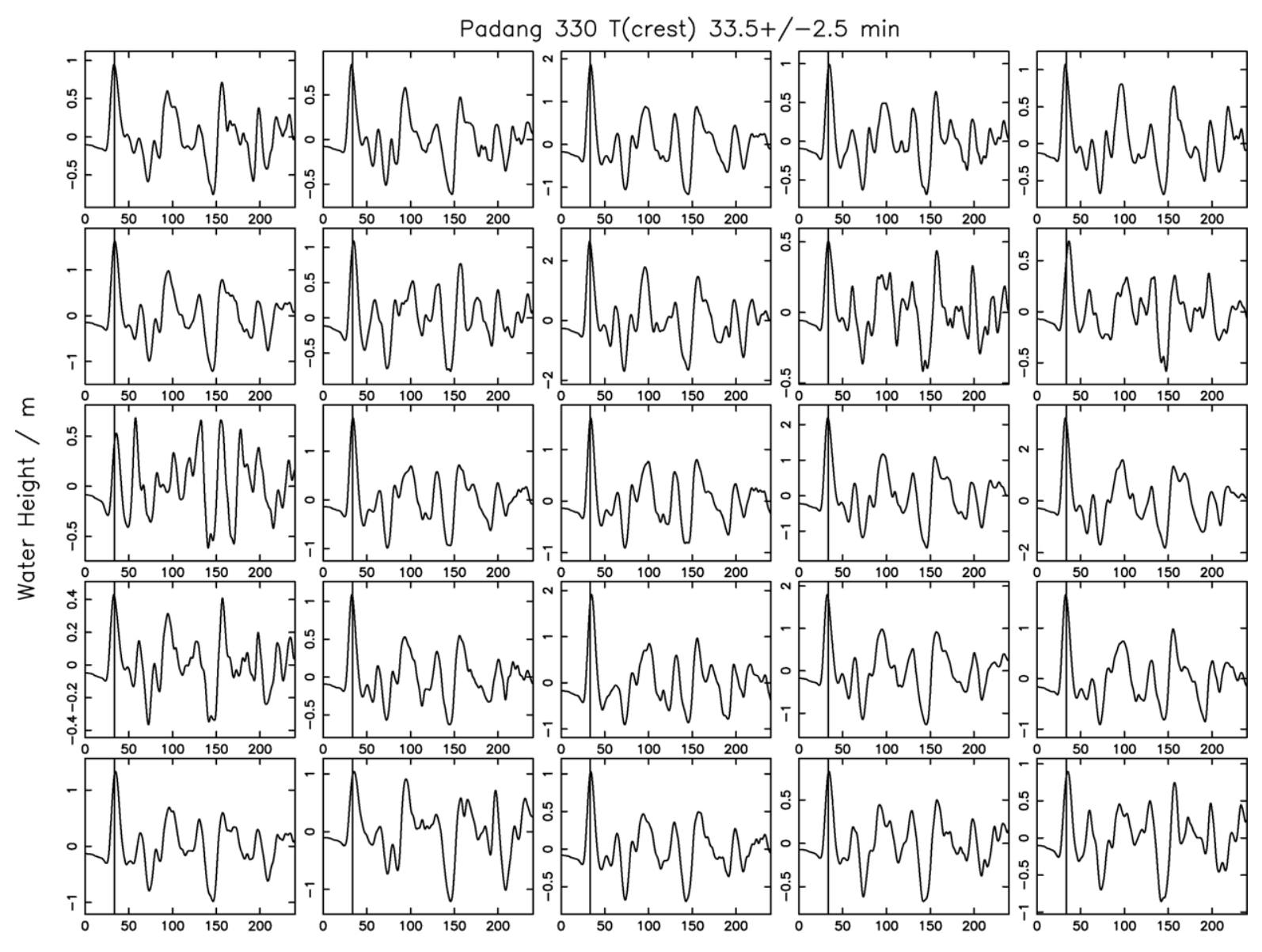

Time After Event Origin/min

Fig. 7. Synthetic mareograms recorded at Padang from all the $330 \mathrm{~km}$ simulations. Note the different scales for the Water Height. Vertical line indicates the average travel time of the first flooding phase for all 100 simulations.

constancy of the bathymetry. The curves for all other segment lengths are essentially the same, indeed the vertical line on each plot records the mean for all 100 simulations; the arrival of the first peak at Padang, for example, occurs $33.4 \pm 2.3(2 \sigma)$ minutes after the event origin. We find similarly bounded arrival times of other phases and for other coastal locations though the shapes of the mareograms and their spectra are the product of interaction of the tsunami wave with the local bathymetry and are, of course unique to each model tide gauge. Whereas, as we have shown above, the energy of the predicted tsunami wave field is extremely sensitive to the distribution of slip, these results show that the timing of inundation of the coast in the near field of the earthquake with respect to the event origin time is remarkably insensitive to the distribution of slip or even to the magnitude. This is particularly surprising given that the event magnitudes range from about M8.1-9.2, the distribution of slip is complex and extremely variable between different simulations and the amplitude of the highest waves in Padang vary from about $10 \mathrm{~cm}$ for some of the $210 \mathrm{~km}$ simulations to almost $10 \mathrm{~m}$ for some of the 630 and $840 \mathrm{~km}$ events. The timing of inundation is essentially the same for all of these cases. As we will show below it would appear that, unlike the predicted wave amplitudes, the timing of the tsunami inundation is governed by the large-scale geometry of megathrust and its control on the longwavelength components of coseismic deformation, rather than the fine-scale detail of the slip distribution.

Fig. 7 exhibits two other important features that are common to all the records at the same near-field location. Firstly, in all but one case, the first arriving phase is the highest, indeed in only seven of the 100 simulations is this not the case. As we will see this observation is important in trying to understand these results. Secondly, 
whereas in every case the height axis was scaled for the maximum and minimum height of the recorded wave train, the vertical coseismic displacement, recorded as the zero time displacement, looks about the same for each event. Thus it would have been possible to have scaled these plots using only the first point. This implies that the vertical coseismic displacement is a good predictor both of the height of the highest wave crest and the depth of the lowest trough. This relationship is shown clearly in Fig. 8 for all the near-field model tide gauges and for all simulations. Note that correlations are significantly higher for Padang and Bengkulu on the Sumatran mainland than for stations on the fore-arc high that are situated near the trench. The sediments of the
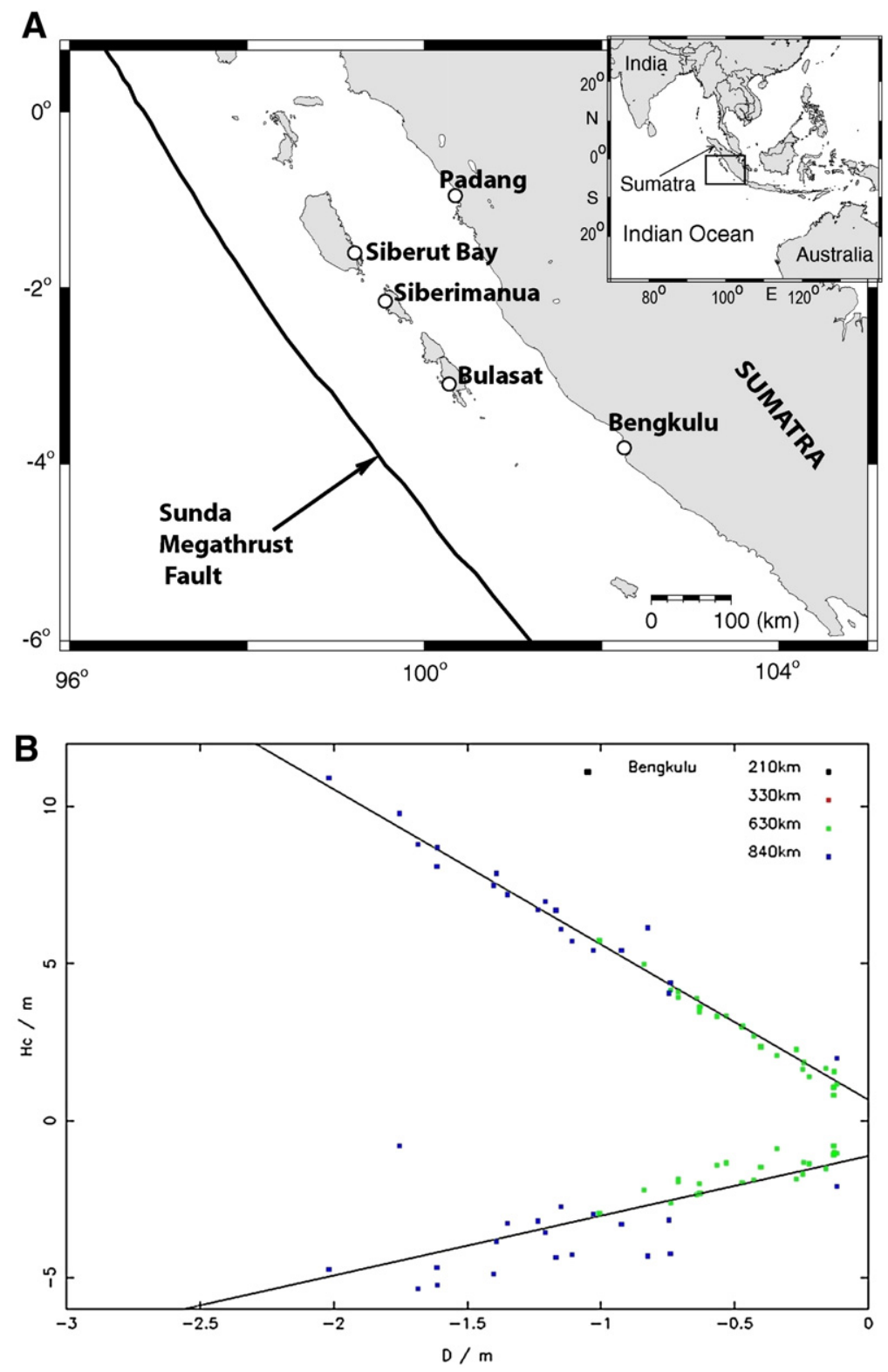

Fig. 8. Dependence of extremes of the observed tsunami on the coseismic displacement at the location of observation. A. Location of simulated tide gauges. B-F graphs of vertical coseismic displacement versus height of highest wave crest (top line) and depth of lowest trough (bottom line) at each station. B. Bengkulu, C. Padang, D. Bulasat on western coast of Selatan Island, E. Siberut Bay south east of Siberut Island and F. Siberimanua on the north coast of Sipura Island. Numbers adjacent to each data set indicate $r^{2}$ value for fit to the straight line. 

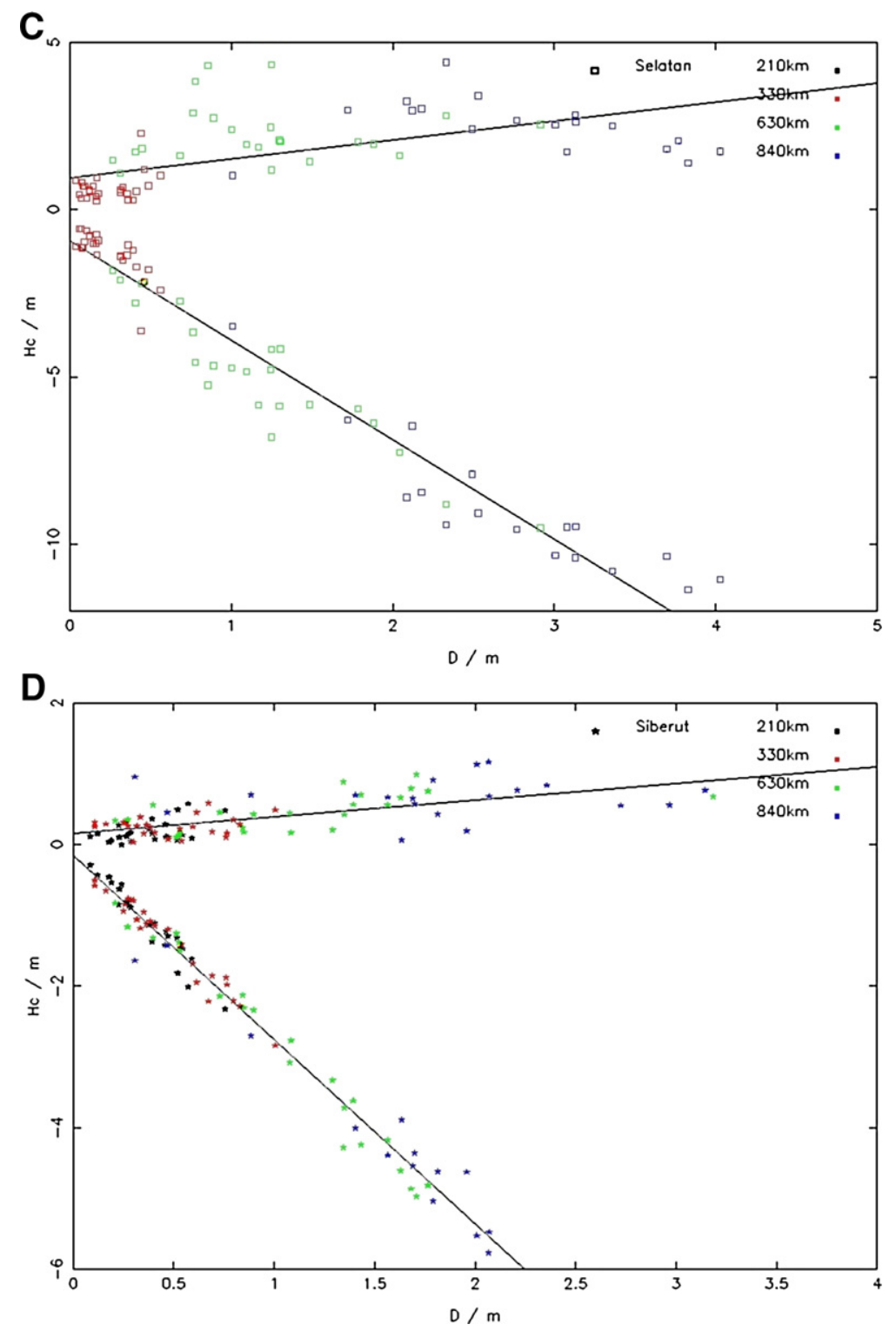

Fig. 8 (continued).

accretionary wedge filter high spatial frequency components of the slip distribution. This filter is more efficient where the wedge is thick.

These results can be explained by reference to the large-scale features of the coseismic deformation. It will be remembered that in more than $90 \%$ of the simulations, for Padang, for example, the highest wave was the first positive wave to reach the coast. This implies that the highest wave is the direct wave from the coseismic emergence of the fore-arc high. The geometry of this emergence is remarkably constant, though its amplitude is not. The geometry of deformation in Figs. 3B and 5A, $\mathrm{B}$ and $\mathrm{c}$ is, for example, broadly the same; the islands go up and the coast goes down. Additionally, the seaward extent of the deformation is bounded by the trench; the landward extent by the lower boundary of seismogenesis at about $35 \mathrm{~km}$ depth and the change in polarity of vertical displacement is to first order half way between. Thus the initial tsunami wave is generated by an approximately sinusoidal vertical displacement that is extended along strike for the length of the failing fault segment. The first, and generally highest, positive phase experienced at Padang is simply the propagation of this initial wave on shore over the fixed bathymetry that takes about the same time, some $33 \mathrm{~min}$. Furthermore, the height of this wave is governed by the coseismic 

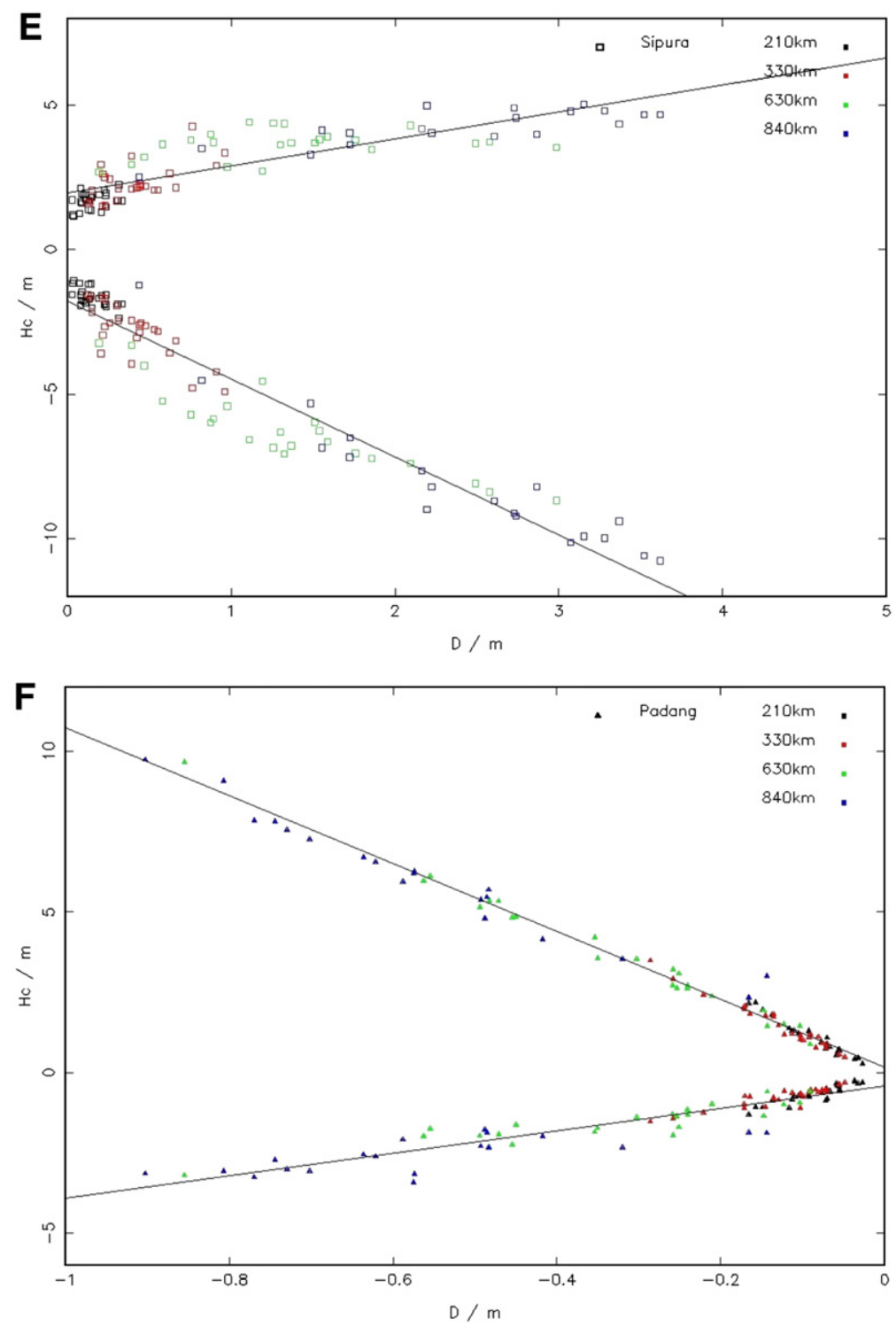

Fig. 8 (continued).

displacement over the islands but since the wavelength and phase of the sinusoidal vertical displacement wave are both fixed, then an estimate of the amplitude of this displacement anywhere along a shore normal profile is strongly correlated with the amplitude of the whole deformation. Thus the wave height observed is predicted by a single estimate of coseismic displacement.

\section{Discussion and conclusions}

The main goal of this project was to examine the threat posed to populations around the Indian Ocean, focusing on western Sumatra, from a megathrust earthquake under the Mentawai Islands and in particular to assess the variability of this threat that stems from the essential unpredictability of the earthquake slip distribution. It has been shown that the threat to distant shores of the ocean from this event is very much smaller than in 2004. Most of the energy is dissipated harmlessly in the Southern Ocean and only locally will wave heights exceed $1 \mathrm{~m}$. Thus it would appear that an ocean wide tsunami warning system, which depends on long wave travel times to allow the identification of the threat and the broadcasting of the warning, will be of limited use for this event.

The threat to western Sumatra, too close to benefit from tsunami warning systems, is very much greater. Simulations here show waves of up to $15 \mathrm{~m}$ off shore of 
some of the centres of high population though the variability of the threat is high with events of the same magnitude resulting in waves with an inherent order of magnitude scatter in predicted height. We note that this scatter is, at least at present, aleatory rather than epistemic since it originates in the variability of the slip distribution that is at present unpredictable. We acknowledge current work (Chlieh et al., submitted for publication) that uses geodetic information to infer the distribution of coupling constants along the megathrust in this area. These results have the potential to constrain the predicted slip distribution, which would likely reduce the variability in the predicted tsunami threat. We are presently carrying out a set of stochastic simulations whose slip distributions are influenced by these results.

In Fig. 6 we have presented the aggregated results for the Sumatran coast and while these results are not in disagreement with the more extreme predictions of previous deterministic studies that use unphysical boxcar slip functions, they show that for many possible events, the threat is considerably less. Thus, for example, while the maximum predicted waves for Padang and Bengkulu are $9.87 \mathrm{~m}$ and $13.04 \mathrm{~m}$ respectively, the equivalent median tsunami heights are $1.86 \mathrm{~m}$ and $0.94 \mathrm{~m}$ respectively, though individual heights are very sensitive to the detail of the slip distribution that cannot be predicted. We acknowledge that our study does not compute the inundation and overland flow depths. Earlier work has shown that, while estimates of near-shore wave heights do in general give first order estimations of run-up height, in some cases local deviations can be considerable. We are presently planning to compute inundations simulations for all the simulated events in this study.

The interaction between bathymetry of the fore-arc complex and the slip distribution on the earthquake is crucial for understanding many features of our results. Some systematics of this interaction are illustrated in Fig. 5. Many possible distributions of slip with high values at intermediate depths on the megathrust produce maximum seafloor displacements, like the SimeulueNias earthquake, in relatively shallow water. Tsunamis thus generated have a relatively small potential energy and do not produce large amplitude waves. Those events with large slip in deep water, close to the trench, generate strong tsunamis that travel southwest across the Indian Ocean basin, but much of their northeast-directed energy is dissipated by interaction with shallow water and islands above the outer-arc high, before they reach the Sumatran coast. Finally, those large moment events with large slip deep on the megathrust, generate vertical seafloor movements in the intermediate water depths $(\approx 1500 \mathrm{~m})$ of the fore-arc basin, thereby producing tsunamis with moderate potential energy that do not encounter shallow water until they are incident on the coast. The south-eastward widening and deepening of the fore-arc basin helps to explain the vulnerability of the southern Sumatran coast to an event with slip deep on the deformation front southeast of Enganno Island. Such an event is, however, thought to be unlikely.

In contrast to the variability of the predicted tsunami wave heights, this study has identified some basic relationships between long-wavelength features of coseismic deformation. The results show that the tsunami travel time to the coast is constant to first order and that the coseismic displacement measured at a point is a good predictor of the maximum wave height that will be experienced at that point. It is not clear whether these results are a peculiar result of the geometry and rheology of Sumatran subduction or whether they represent universal relationships that will be observed for other regions. It is important that similar studies are carried for other regions to investigate the behaviour there and that existing data should be examined for evidence of these relationships for past earthquakes. It is not, however, clear that the appropriate data will exist. The only tide gauge in the near field of the SimeulueNias earthquake, for example, which might have produced one example, is digitised at 10 min intervals and while its records are consistent with the predictions of this study, their poor resolution of both the timing and maximum height of the tsunami is inconclusive. It is a strong recommendation of this paper that high frequency tide gauges with are installed along the Sumatran coast on shore of the Mentawai Islands so that detailed measurements of any future tsunami might be able to falsify our predictions. This will also involve detailed and high-resolution geodetic surveys of the coast so that the vertical coseismic displacement might also be estimated after the earthquake.

These results are important in the preparation of circum-Indian Ocean populations for the threatened Mentawai megathrust event. On a regional basis, our results indicate generally small wave heights at sites far from the source around the Indian Ocean. Some modelled waves of more than $0.5 \mathrm{~m}$, however, suggest a need for more detailed simulations over high resolution, nearshore bathymetric models of Sri Lanka, east Africa, northwestern Australia and the Indian Ocean Islands, as has been done here for western Sumatra, to examine the possibility of amplification by local bathymetric features. We recommend that these studies be carried out for all centres of population on Indian Ocean coasts and will 
make our shallow water wave height predictions available to assist any such efforts. Finally, while our results for western Sumatra indicate a smaller tsunami hazard when compared to those experienced in Aceh province in 2004, about half of the simulations in this study predict tsunami inundation at major centres of population in western Sumatra with the potential to cause great loss of life. Furthermore, because of the small modelled travel times, the Indian Ocean tsunami warning system is unlikely to mitigate this threat. However the earthquake itself will produce strong ground shaking along the entire central western Sumatran coastline, and the time between the end of strong shaking and the first tsunami maximum will typically be about $25 \mathrm{~min}$. This study fully vindicates the conclusions of the earlier studies in this regard and underscores the urgency of careful planning and preparedness training that could exploit this delay to optimize rapid evacuation from those areas that are most susceptible to tsunami inundation.

\section{Acknowledgments}

We thank Rory Quinn for assistance in the bathymetric modelling and Spina Cianetti for assistance in construction of the finite-element model of subduction. The Landsat ETM+ data is used courtesy of the Global Land Cover Facility, (http://www.landcover.org). We are grateful for financial support from NERC Grant Number NER/ D006678/1. We acknowledge the constructive and helpful comments of Joan Gomberg and an anonymous reviewer.

\section{References}

Banerjee, P., Pollitz, F., Nagarajan, B., Bürgmann, R., 2007. Coseismic slip distributions of the 26 December 2004 Sumatra-Andaman and 28 March 2005 Nias earthquakes from GPS static offsets. Bull. Seism. Soc. Am. 97 (1A), S86-S102.

Borrero, J.C., Sieh, K., Chlieh, M., Synolakis, C.E., 2006. Tsunami inundation modeling for western Sumatra. PNAS 103, 19673-19677.

Briggs, R.W., et al., 2006. Deformation and slip along the Sunda megathrust in the great 2005 Nias-Simeulue earthquake. Science 311, 1897-1901.

Chlieh, M., et al., 2007. Coseismic slip and afterslip of the Great (Mw9.15) Sumatra-Andaman Earthquake of 2004. Bull. Seismol. Soc. Am. 97, S152-S173.

Chlieh, M.J.P., Avouac, K., Sieh, D.H., Natawidjaja, John Galetzka, submitted for publication. Heterogeneous coupling on the Sumatra megathrust constrained from geodetic and paleogeodetic measurements JGR

Geist, E.L., 2002. Complex earthquake rupture and local tsunamis. J. Geophys. Res. 107 (B5). doi:10.1029/2000JB000139.

Geist, E.L., Parsons, T., 2006. Probabilistic analysis of tsunami hazards. Natural Hazards 37, 277-314.

Geist, E., Bilek, S.L., Arcas, D., Titov, V.V., 2005. Differences in tsunami generation between the December 26, 2004 and March 28, 2005 Sumatra earthquakes. Earth Planets Space 58, 185-193.
Gomberg, J., Ellis, M.A., 1994. Topography and tectonics of the New Madrid seismic zone: results of numerical experiments using a three-dimensional boundary element program. J. Geophys. Res. 99, 20299-20310.

Habermann, R.E., McCann, W.R., Perin, B., 1986. Spatial seismicity variations along convergent plate boundaries. Geophys. J. R. Astron. Soc. 85, 43-68.

Henry, C., Das, S., 2001. Aftershock zones of large shallow earthquakes: fault dimensions, aftershock area expansion and scaling relations. Geophys. J. Int. 147, 272-293.

Hsu, Y., Simons, M., Avouac, J.-P., Galetzka, J., Sieh, K., Chlieh, M., Natawidjaja, D., Prawirodirdjo, L., Bock, Y., Subarya, C., 2006. Frictional afterslip following the 2005 Nias-Simeulue earthquake, Sumatra. Science 312, 1921-1926.

http://www.tsunami.civil.tohoku.ac.jp/sumatra2004/report.html, Comprehensive analysis of the damage and its impact on coastal zones by the 2004 Indian Ocean tsunami disaster, a special report.

Kopp, H., Weinrebe, W., Ladage, S., Barckhausen, U., Klaeschen, D., Flueh, E.R., Gaedicke, C., Yusuf, M.D., the SeaCause and GITEWS Teams, 2001. Lower plate impact on earthquake rupture segmentation on the Sumatra margin. Geophys. J. Int. 147, 449-474.

Kopp, H., Fajar, S., Djajadihardja, Y., 2006. Bathymetric survey images structure off Sumatra. EOS Transactions 87 (17), 165-172.

Leblond, P., Mysak, L.A., 1978. Waves in the Ocean. Elsevier, Amsterdam. 602 pp.

Mader, C.L., 2004. Numerical Modelling of Water Waves. CRC Press LLC.

Mai, P.M., Beroza, G.C., 2002. A spatial random-field model to characterize complexity in earthquake slip. J. Geophys. Res. 107, 2308. doi:10.1029/2001JB000588.

McCloskey, J., Nalbant, S.S., Steacy, S., 2005. Earthquake risk from co-seismic stress. Nature 434, 291.

McCloskey, J., Antonioli, A., Piatanesi, A., Sieh, K., Steacy, S., Nalbant, S.S., Cocco, Massimo, Giunchi, Carlo, Huang1, JianDong, Dunlop1, Paul, 2007. Geophys. Res. Lett. 34, L14316. doi:10.1029/2007GL030494.

Nalbant, S.S., Steacy, S., Sieh, K., Natawidjaja, D., McCloskey, J., 2005. Earthquake risk on the Sunda Trench. Nature 435, 756-757.

Natawidjaja, D.H., et al., 2004. Paleogeodetic records of seismic and aseismic subduction from central Sumatran microatolls, Indonesia. J. Geophys. Res. 109. doi:10.1029/2003JB0002398.

Natawidjaja, D.H., et al., 2006. The giant Sumatran megathrust ruptures of 1797 and 1833: Paleoseismic evidence from coral microatolls. J. Geophys. Res. 111. doi:10.1029/2005JB004025.

Newcomb, K.R., McCann, W.R., 1987. Seismic history and seismotectonics of the Sunda Arc. J. Geophys. Res. 92, 421-439.

Okal, E., Synolakis, C., 2004. Source discriminants for near-field tsunamis. Geophys. J. Int. 158, 899-912.

Piatanesi, A., Lorito, S., 2007. Rupture process of the 2004 SumatraAndaman earthquake from tsunami waveform inversion. Bull. Seismol. Soc. Am. 97, S223-S231.

Pollitz, F.F., Banerjee, P., Burgmann, R., Hashimoto, M., Choosakul, N., 2006. Stress changes along the Sunda trench following the 26 December 2004 Sumatra-Andaman and 28 March 2005 Nias earthquakes. Geophys. Res. Lett. 33, L06309. doi:10.1029/ 2005GL024558.

Prawirodirdjo, L., et al., 1997. Geodetic observations of interseismic strain segmentation at the Sumatra subduction zone. Geophys. Res. Lett. 24 (21), 2601-2604.

Satake, K., 2002. Tsunamis. In: Lee, W.H.K., Kanamori, H., Jennings, P.C., Kisslinger, C. (Eds.), International Handbook of Earthquake and Engineering Seismology. Academic Press, San Diego, pp. 437-451. 
Scholz, C., 1990. The Mechanics of Earthquakes and Faulting. Cambridge Univesrity Press.

Steacy, S., McCloskey, J., 1999. Heterogeneity and the earthquake magnitude-frequency distribution. Geophys. Res. Lett. 26 (7), 899-902.

Subarya, C., Prawirodirdjo, L., Avouac, J.P., Bock, Y., Sieh, K., Meltzner, A.J., Natawidjaja, D.H., McCaffrey, R., 2006. Plate-boundary deformation associated with the great Sumatra-Andaman earthquake. Nature 440, 46-51. doi:10.1038/nature04522.
Tucker, C.J., Grant, D.M., Dykstra, J.D., 2004. NASA's global orthorectified Landsat data set. Photogramm. Eng. Remote Sensing 70, 313-322.

Turcotte, D.L., Schubert, G., 2002. Geodynamics, 2nd ed. Cambridge University Press, Cambridge. 456 pp.

Vigny, C., et al., 2005. Insight into the 2004 Sumatra-Andaman earthquake from GPS measurements in southeast Asia. Nature 436, 201-206. doi:10.1038/nature03937. 